\title{
Marie-Antoinette et ses biographes : histoire d'une écriture de la Révolution française
}

\section{Sylvie Dallet}

\section{(2) OpenEdition \\ 1 Journals}

\section{Édition électronique}

URL : https://journals.openedition.org/ahrf/8723

DOI : 10.4000/ahrf.8723

ISSN : 1952-403X

Éditeur :

Armand Colin, Société des études robespierristes

\section{Édition imprimée}

Date de publication : 1 mars 2007

Pagination : 187-188

ISSN : 0003-4436

\section{Référence électronique}

Sylvie Dallet, "Marie-Antoinette et ses biographes : histoire d'une écriture de la Révolution française », Annales historiques de la Révolution française [En ligne], 347 | janvier-mars 2007, mis en ligne le 21 juillet 2008, consulté le 23 avril 2022. URL : http://journals.openedition.org/ahrf/8723 ; DOI : https://doi.org/ 10.4000/ahrf.8723

Ce document a été généré automatiquement le 23 avril 2022.

Tous droits réservés 


\title{
Marie-Antoinette et ses biographes : histoire d'une écriture de la Révolution française
}

\author{
Sylvie Dallet
}

\section{RÉFÉRENCE}

Cécile Berly, Marie-Antoinette et ses biographes : histoire d'une écriture de la Révolution française, Paris, L'Harmattan, 2006, 174 p., ISBN 2-296-01223-X, $16 €$.

1 L'ouvrage universitaire de Cécile Berly, Marie-Antoinette et ses biographes, Histoire d'une écriture de la Révolution française, confronte les portraits de la reine brossés par cinq historiens contemporains, du milieu du XIX siècle aux années 1990. Ces cinq auteurs en quête d'un même personnage, ondoyant, magnifique ou pitoyable, ont consulté les archives, les ont diversement interprétées et se sont fait connaître du grand public par des sommes bien écrites. Le témoignage de Cécile Berly, plus concis, apparait alors comme un véritable défi intellectuel aux auteurs cités: elle reprend les analyses des frères Goncourt (1858), de Stephan Zweig (1934), de Jean Chalon (1988), de Paul et Pierrette Girault de Coursac (1990) et d'Évelyne Lever (1991), sous la forme d'une confrontation raisonnée, assaisonnée du sel «scientifique», alors que les écritures étudiées sont présentées comme "vulgarisatrices».

2 Évoquer les interprétations de l'histoire et particulièrement celles qui sont liées à la peinture des caractères est un exercice délicat parce qu'il ne peut se faire dans l'innocence des enjeux symboliques. Cécile Berly pressent ce substrat quand elle écrit : « aux femmes sans présence historique s'opposerait cette reine - femme à la mémoire saturée ». L'ouvrage repose sur un argumentaire thématique qui fait le va et vient entre des époques distinctes, dans une écriture neutralisée qui, au-delà du souci "scientifique " régulièrement invoqué, cherche foncièrement à ne pas ranimer les passions inhérentes au genre. Cécile Berly offre au lecteur ces deux qualités nécessaires 
pour le citoyen comme pour l'historien, du courage (parfois de la naïveté téméraire) et un certain talent de plume. Son écriture de l'histoire se situe, de fait, au point de rencontre de deux expressions sensibles, celle de la souveraine et celle de la comparatiste, sur des modes de dédoublement et d'identification que Cécile Berly observe attentivement sur les biographes dont elle étudie la conception.

Cependant, malgré ces atouts qui rendent la lecture agréable, car fine et bien écrite, le travail de Cécile Berly laisse une impression mitigée, parce qu'il revendique une spécificité d'écriture savante, sans entrer dans les définitions et donc dans un possible conflit. La comparaison systématisée met en danger l'écrivain chercheur, car sa rédaction exige à la fois une narration et un essai, dans une relation exigeante à la fois conceptuelle et historiquement documentée. Or, cette navigation intellectuelle n'évite pas ici quelques redondances, révélant, au détour d'une formule prudente ou osée, un défaut d'appareil critique et de références (pour exemple les travaux pionniers d'Alice Gérard et de l'équipe de Jean-Claude Bonnet ne sont pas utilisés). Pour s'arrêter au vocabulaire de la « vulgarisation » dont l'auteure use parfois sans modération, quelques maladresses d'opinion desservent la leçon de courage que Cécile Berly entend donner à son lecteur.

Le délicat exercice de la biographie se rattache à l'histoire des sensibilités et au «mental» cher à Lucien Febvre: le travail de repérage qu'il suppose exige une réévaluation constante du contexte politique et social, à l'équilibre entre la pudeur et la passion des êtres. Alors que quelques phrases introductives rappellent que toute biographie reste liée avec une historiographie qu'elle traduit, exalte ou réoriente, l'auteure hésite à en dévoiler les lignes de force, peut-être sous la pression d'une logique éditoriale qui a tronqué l'exercice universitaire initial.

De fait, les œuvres sont peu étudiées au travers leur accueil public, leurs dates de parution, voire leur proximité avec les commémorations, tout cet arrière-plan qui commandite, reçoit et oriente in fine le sens commun de l'histoire. Par ailleurs, si les biographies sont rarement évaluées au regard de la production historiographique écrite, l'essai critique néglige totalement le premier outil de vulgarisation contemporain que demeure l'audiovisuel. Même si l'écriture analysée par Cécile Berly se résout à cinq exemples populaires maintes fois réédités, on ne peut passer sous silence que l'année 2006 restera l'année de la biographie imagée de Sofia Coppola, comme l'année 1939 celle de la version américaine de Woodbridge Strong van Dyke (le «certain » van Dyke, selon le terme approximatif de Cécile Berly en note de bas de page). Ces mises en scènes simplifiées et efficaces touchent un public bien plus large que les ouvrages analysés par l'historienne universitaire, qui mentionne toutefois, en conclusion, la floraison des sites Internet consacrés à la souveraine. En d'autres termes, l'exercice biographique ne peut se satisfaire d'une seule focale sur le portrait et son biographe, même si ce couple est décrit transversalement par la genèse de l'œuvre.

6 Parmi les croquis des écrivains qu'elle étudie, Cécile Berly laisse percer (et pourquoi pas ?) son admiration pour la subtilité psychologique de Stefan Zweig. À sa suite, sur un chapitre complet, elle explore les fantasmes du corps (et du sexe) royal, exposé, profané, mis en scène. Cette approche sensible (le mot n'est pas de Cécile Berly qui évite cet adjectif) s'affirme en ce début de siècle, comme la voie royale des historiens, renforcé par notre civilisation de l'image. Cette forme narrative rejoint paradoxalement les audaces expérimentales, voire cliniques, du siècle dernier. 
7 Cependant, à trop suivre Marie-Antoinette dépeinte au détour des perceptions de ses biographes, au regard de quelques historiens contemporains choisis comme référents obligés, l'auteure tisse au petit point des portraits à fond noir, où l'avis du lecteur reste captif, sans pouvoir se déprendre, de la tête, du corps chatoyant ou des atours de circonstance de la reine.

Or, comme l'art du peintre, le genre biographique reste un symptôme révélateur de son époque, entre l'histoire des idées et celle des mentalités. Les formes du récit biographique, tour à tour éclatantes ou ombrées, laissent à deviner les atours et les alentours d'un sujet vivant, Marie-Antoinette, qui, reine de France, devient, contre son gré, l'objet dompté de l'histoire et de ses écrivains. La relation entre le passé remémoré et les multiples symboliques de la représentativité institutionnelle demeure le véritable enjeu de la mise en scène du pouvoir et de son écriture savante.

9 Dans cette confrontation biographique, qui conjugue ici une triple approche comparatiste, féministe et sensible, l'abondance des matériaux, leur caractère hétérogène doivent servir paradoxalement la démonstration scientifique, au-delà des bons et des mauvais points décernés au biographe. Une mise en perspective constante, culturelle et sociale, peut-être même franchement décalée, permettrait d'éviter certains effets de loupe ou de redondances, qui révèlent, malgré la nature courageusement comparative de l'exercice, une affectivité positiviste qui hésite entre les petits liens nécessaires et le sel des anecdotes. L'historienne ne peut ignorer que la logique floue, même novatrice, demeure une navigation à risque : cet art de la défense doit, pour être mené au plus vrai du sujet (et convaincre son lectorat "savant»), corseter ses intuitions d'une solide connaissance des observatoires éloignés, miroirs du temps et de l'espace, dans un tournoiement collectif, où le politique, le philosophique et le social se disputent sensiblement depuis plus de deux cents ans l'image de la Reine. 